\title{
Material Name with Attribute Name
}

National Cancer Institute

\section{Source}

National Cancer Institute. Material Name with Attribute Name. NCI Thesaurus. Code C93865.

A non-unique textual identifier for the material. 